
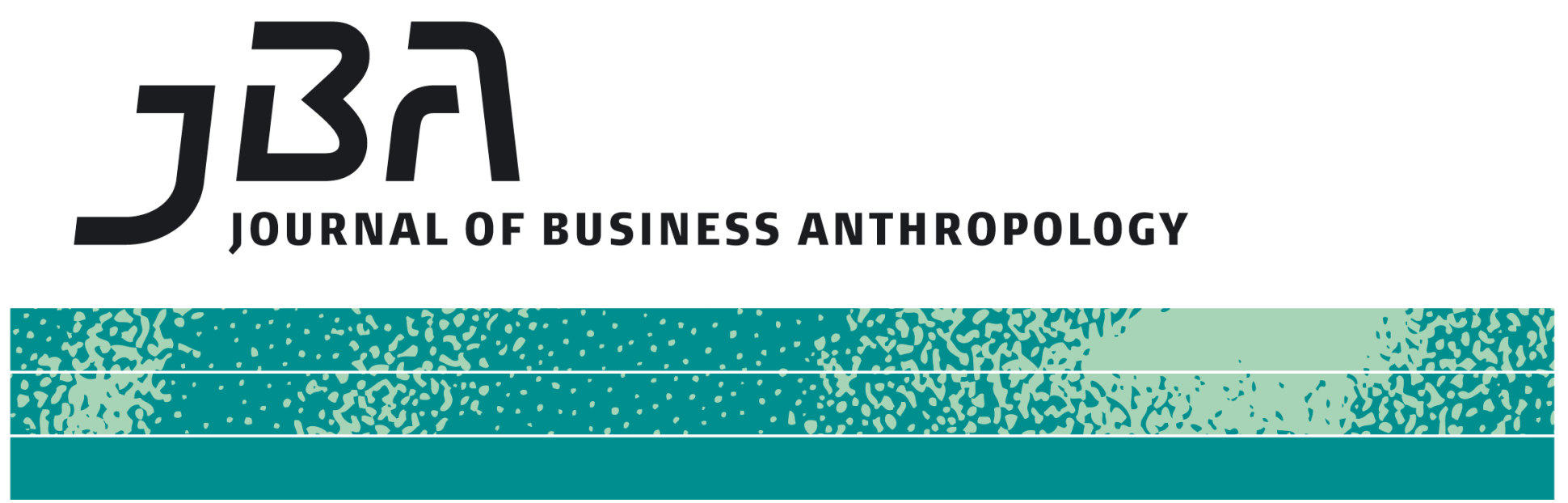

\title{
Ritual, Embodiment and the Paradox of Doing the Laundry
}

Maryann McCabe

\begin{abstract}
Paradox often provides a starting point for cultural analysis of consumer behavior. The paradox of the laundry in which mothers find the laundry a boring and repetitive task yet hesitate to relinquish the chore to others is examined through the embodied experience of women's laundry rituals. Performance of the ritual generates feelings of competence in cleaning clothes to an absolute standard of cleanliness and feelings of caring, nurturance and love of family. For mothers, the ritual goal of cultivating subjectivity in children about presentation of self to the world depends on drawers full of clean clothes. Laundry rituals are transformative because they ignite and renew emotions relating to a perceived parental role. This article discusses implementation of anthropological practice in terms of incorporating ethnographic research findings into advertising communications. In the implementation process, agency is key in bridging discourse of mothers and discourse of advertising and in producing culture.
\end{abstract}

\section{Keywords}

Paradox, ritual, embodiment, agency, subjectivity, materiality
Page 1 of 24

JBA 7(1): 8-31

Spring 2018

(C) The Author(s) 2018 ISSN 2245-4217

www.cbs.dk/jba 


\section{Introduction}

Doing the laundry creates a paradox for women. "I hate doing the laundry, but I can't stand it when someone else does it," a refrain heard from mothers, poses grist for the anthropological mill. Paradox offers a starting point for cultural analysis compared to paradoxical but logical endings in logics. To explain the laundry paradox, this article examines meanings of the laundry process in the embodied experience of women. Doing the laundry is hated because it is a boring, never-ending and often thankless task. As household labor and unpaid work, laundry is a debated source of gender oppression (DeVault 1991, Hochschild 1989). Yet, based on the construction of meaning and the transformation of self that takes place in laundry rituals, doing the laundry holds importance for mothers because it awakens and affirms a key aspect of parenting. Women rely on drawers full of clean clothes to teach their children about presentation of self to the world and to cultivate subjectivity or self-awareness about how they present themselves in public. This teaching practice is interrupted should other persons in the household do the laundry and not do it correctly. The laundry paradox is resolved through ethnographic understanding of the emotions and intentions of mothers who perform laundry rituals.

The article is oriented to showing how ethnographic findings from consumer research are used in advertising. In the laundry case, a detergent manufacturer incorporated meaning from women's laundry rituals into communications with a target audience. The concept of agency became critical in efforts to reach consumers. Brand communications shifted emphasis of agentic force from the product and cleaning dirty clothes to women and emotions concerning their children and presentation of the self. As the article argues, the practice of doing consumer research in anthropology is implicated in the creative and political process of producing advertising campaigns (Malefyt and Moeran 2003).

The next section of the article introduces a theoretical approach to paradox, ritual, subjectivity and agency. Following sections present methodology and findings from an ethnographic study conducted for a corporation that manufactures laundry products. Then there is discussion on implementation of research results in the social discourse of advertising communications and on implications for theories of materiality.

\section{Theoretical approach}

\section{Paradox}

The idea of paradox has been defined and employed in a number of disciplines including logics, mathematics, philosophy and anthropology. In the field of logics, Quine (1966) speaks about veridical or truth-telling 
paradoxes, which refer to examination of statements that conclude a proposition seems to be absurd but is demonstrated to be true. As Quine writes, a paradox is a "conclusion that at first sounds absurd but has an argument to sustain it" (1966: 1). In anthropology, on the contrary, paradox constitutes a departure for cultural analysis. When paradox arises in ethnographic contexts, it becomes a starting point to pursue explanation of people's practices (Malefyt and McCabe 2016).

In the seminal work of Mary Douglas (1966), paradox emerges in experience when the experience does not fit into a cultural system of classification and, therefore, creates ambiguity and anomaly. Dirt, she famously stated, is "matter out of place" (1996: 48). As she explicates, paradox "is an attempt to force experience into logical categories of noncontradiction. But experience is not amenable and those who make the attempt find themselves led into contradiction" (1996: 192). Cultural categories underlying women's laundry practices are abrogated by actions that do not fit within the classificatory system of steps for doing the laundry. For example, husbands who do not sort dirty clothes by color and type of fabric before putting them in the washing machine broach categories that prescribe how to do the laundry correctly. Such behavior is risky and dangerous because, as Douglas writes, "it is destructive to existing patterns" (1996: 114). In practical terms, the outcome of improper sorting of dirty clothes could be color bleeding and the ruin of clothing. Symbolically, proper sorting eliminates disorder and restores a cultural system of classification.

To do laundry correctly or incorrectly, right or wrong, invokes aesthetics. As the sensory contemplation or appreciation of an object, aesthetics applies to laundry. Mothers subscribe to an absolute notion of clean where dirty clothes should be returned to their original state, "like when they were brand new," as a participant, Lisa, mother of 3 children, described. However, laundry aesthetics go beyond subjective judgments of cleanliness and involve a larger cultural system of meanings and values. In an ethnographic study of Japanese potters, Moeran (1997) posits that aesthetics refer,

...firstly, to the effects that physical properties of objects have on the senses (the form, the feel and weight of pots, for example, together with the textures and colours of the clays and glazes used in folk craft pottery); and secondly, to other non-material attributes perceived in objects and which become 'aesthetic' when incorporated into a socio-cultural system of values and meanings (in the context of the Japanese Mingei movement, for instance, such attributes as 'cooperative beauty' and 'natural' methods of production). (1997: 9)

The values and meanings in which the laundry process is embedded are expressed in women's laundry rituals. Thus, explaining the 
paradox calls for understanding (1) the cognitive frame of cultural categories for doing the steps in the laundry process and judging the aesthetic outcome, and (2) the emotional frame of embodied experience occurring in laundry rituals where meaning and values are enacted. Embodiment refers to perceiving and acting on the world through the medium of the body and the senses (Csordas 1990, Desjarlais and Throop 2011). Based on a phenomenological approach to understanding behavior in the work of Thomas Csordas and Maurice Merleau-Ponty, embodiment is "the essential ground of existence and experience" (Csordas 2012: 60).

\section{Ritual}

Anthropological studies of ritual have long recognized that ritual organization, action, and transformation are representations of broader cultural and social orders (Handelman and Lindquist 2005). Laundry rituals, for instance, represent the division of labor by gender in society. However, following work by Victor Turner (1967) on ritual as process, recent anthropological studies of ritual focus on ritual performance as means to bring about transformation through its own dynamics. A performative view of ritual acknowledges the emotions and heightened moments of self-awareness experienced by persons engaged in ritual acts. As Stewart and Strathern (2014) state, "The embodied participation of persons in rituals not only influences them in bodily ways but becomes the actual vehicle by which metaphorical meanings are created and credited with efficacy" (2014: 5). In laundry rituals, cleanliness signifies both the transformation of dirty clothes into clean clothes and metaphorically the emotions of caring and nurturance that mothers feel during the laundry process. These emotions inspire mothers to impart subjectivity or self-awareness about presentation of the self to their children. For women, the significance of doing laundry is expressed internally in ritual.

Ritual involves emotional acts experienced in the body (Svasek 2005). With the laundry, women's emotional experience comes from sensual interactions with things (clothing, products, machines) and through mnemonics and remembering social occasions when clothes were worn. For example, collecting, touching and sorting dirty clothes brings into memory the emotions of specific family moments and times together, while folding clean clothes that smell fresh and still feel warm from the dryer creates and recreates desire in mothers to teach their children about choosing clothing as part of presenting the self.

Ritual is generative and transformative because it joins two forms of practice, namely cognitive knowledge and emotional knowledge (De Witte 2011). Mothers have cognitive knowledge about how to make dirty clothes clean and emotional knowledge about family experiences and the feelings attached to them that they recall and re-live. These embodied 
emotions connect with a mother's identity and affect as a caring and nurturing parent who wants her children to look good and feel good in the way they dress everyday. In the laundry ritual, women are not only accomplishing a repetitive household chore but also transforming the self as parent. Since ritual acts are reflexive, they are sites for producing emotion and making participants aware of meanings and values. As Maschio (2015) affirms, "I do believe consumer rituals often reveal people to be engaged in performances that enable them to see or perceive or create the deeper meanings of their everyday activities and of the objects they interact with. Further, these rituals have an emotional payoff and objective. They are often emotionally satisfying to perform, and the performance is meant to evoke certain emotional states" (2015: 345).

\section{Subjectivity}

Subjectivity, a central concept in philosophy, has been used over the last two decades by anthropologists concerned with cultural issues in numerous fields such as medical anthropology, psychological anthropology, and environmental anthropology. In anthropological studies, the concept of subjectivity generally refers to self-awareness. According to Luhrmann (2006), subjectivity has a general and a particular referent in anthropology. It refers (1) "to the shared inner life of the subject, to the way subjects feel, respond, experience" (2006: 345), and (2) "particularly to the emotional experience of a political subject, the subject caught up in a world of violence, struggle and oppression" (2006: 356). It is the first of the two referents that provides traction for understanding laundry rituals. Mothers cultivate subjectivity in their children about presentation of the self. A drawer full of clean clothes provides opportunity for mothers to interact with children about choices they make when getting dressed. Mothers discuss choices in terms of emotions, how a child feels, which clothes reflect the feelings, and how the child wants to look in front of others. These conversations about daily wardrobe decisions are meant to develop self-awareness in children about presenting themselves in public.

Subjectivity is inextricably joined with intersubjectivity (Skoggard and Waterston 2015, Csordas 2012) and positioning the self in relation to others (Holland and Leander 2004). Privileging the social in conceptualizing presentation of the self enjoys a long tenure in social science starting with Goffman (1956) and framing social situations in face-to-face interactions to manage impressions others will have of the self. Building on this idea of projecting an image or face, recent studies of subjectivity focus on the formation of embodied affect. As Holland and Leander (2004) note, social positioning of persons and groups is "a primary means by which subjects are produced and subjectivity forms" (2004: 127). When mothers talk about what clothes to wear, they are 
teaching their children to become self-aware of emotions and public display to others. Getting dressed is an experience of the body and a public presentation of it (Entwistle 2015). As Entwistle writes, "Dress is the way in which individuals learn to live in their bodies and feel at home in them" (2015: 7).

Agency

Women's discourse of the laundry process originates in embodied practice. This discourse emphasizes aesthetics of clean clothes, caring and nurturing for the family, and cultivating subjectivity in children for presentation of self. Laundry discourse and ritual express agency and the intentions and actions of mothers. Agency, the sociocultural mediated capacity to act (Ahearn 2011: 112) and the capacity to create effects in the world (Miyazaki 2004: 7), became a pivotal point for implementing ethnographic research findings in advertising communications.

For many decades Procter \& Gamble, manufacturer of Tide, market leader in the laundry detergent category, has highlighted the power of its product to clean clothes. Advertising features this power in terms of ingredients and efficacy as well as corporate success over competitors in market leadership. Advertising discourse emphasizes agency of objects in the cleaning regime. However, in the discourse of mothers, agency refers to competence in doing the laundry and achieving aesthetic results as well as to fulfilling perceived roles as nurturers and educators in the family. At the conclusion of this ethnographic study and presentation of findings to clients, client discussions grappled with shifting consumer outreach from product focus to incorporating the embodied perspective of mothers. The laundry assemblage, bringing together people and things as actors, carries implications for understanding material culture.

\section{Methodology}

Procter \& Gamble and its advertising agency, Saatchi \& Saatchi, commissioned ethnographic work and contracted the author as ethnographer to conduct it. A letter of intent from Saatchi to P\&G claimed need for new knowledge about the meaning of laundry in women's lives:

"On detergents, we have a good understanding of the more factual, 'left-brained' aspects of the business (e.g., consumer needs, brand ratings, usage patterns, loyalty, etc.)."

But, the letter continued,

"The learning opportunity for the entire Tide brand lies in a more thorough understanding of the emotional aspects of the laundry process." 


\section{In-home interviews and tape diaries}

The clients, Procter \& Gamble and Saatchi \& Saatchi, chose a target audience of white middle-class mothers with two or more children under 18 living in the home. In-home interviews were conducted with a total of 20 women, each of whom completed a tape diary prior to the visit by the ethnographer. Interviews were conducted in Rochester, NY $(n=14)$ and Toronto $(n=6)$.

Research participants were recruited to capture differences in age (half 18-29, half 30-49 years old), annual household income (half $\$ 20$ 50,000 , half $\$ 50,000+$ ), and laundry characteristics including type of detergent used ( $1 / 2$ liquid, $1 / 2$ powder), price (mix of premium, medium and low price brand users), and regular or occasional use of other laundry products such as bleach and pre-treating stain removers. Only mothers who did at least five loads of laundry per week qualified to participate in the study.

The ethnographer developed an open-ended questionnaire for the in-home interviews, which lasted two hours or more, and covered the history of laundry practices, current routines, learning about new products and ways of doing the laundry, and family interactions over the laundry process. The loosely structured discussion guide let the interviews evolve (Thompson and Haytko 1997) so that the ethnographer could listen and observe moments of opportunity in the conversation. As women discussed their laundry routines, the ethnographer listened for descriptions of boredom, frustration, contentment, anticipation and so forth. These emotional cues signaled the ethnographer when to probe further or when to move onto another topic.

In-home interviewing included observation of the laundry process. Steps observed were collecting, sorting, pre-treating, washing, drying, folding and putting away the clothes. Conversation between ethnographer and participant during observation focused on goals, outcomes and emotional involvement at each step. Photos of the steps were taken in the home at the discretion of participants.

Respondents kept tape diaries for five days prior to the interview. They recorded once a day while doing laundry at home and once in the laundry aisle of a supermarket. The ethnographer developed written guidelines on topics to address in the tape diaries, which were sent to each participant ahead of time. For recordings of the laundry process at home, topics included description of steps being done at the time, thoughts and feelings that surfaced during each step, and reflections afterward on the laundry routine. Topics for the supermarket visit included reactions to products in the aisle, selection behavior, reasons for choosing products, and emotions experienced in the laundry aisle compared to other supermarket aisles. Average tape diary length was 30 minutes. 


\section{Analysis}

Analysis of the ethnographic data proceeded by text, performance and discourse analysis. The hand-written notes taken by the ethnographer during interviews and the participant recordings in tape diaries were examined as text for representations (Van Maanen 2011). The purpose of this analysis was to identify cultural categories underlying steps of the laundry process and emotional themes accompanying laundry practices. Analysis of embodied experience in the performance of laundry rituals was oriented to finding "an emotional tone or mood common to a group of people" (Luhrmann 2006: 348). The intent of discovering shared sentiments among participants was to realize how responses to the aesthetics of doing laundry either correctly or incorrectly support or interfere with the goals of mothers. Finally, discourse analysis of naturally occurring talk (Potter 2004) aimed to provide an interpretive framework of assumptions about the self and laundry products. This analysis, based on women's talk in tape diaries and client talk during presentation of the study results, sought to compare the discourse of mothers and the discourse of advertising and implications for changing communications to consumers.

\section{Findings}

\section{Boredom and never-ending pressure}

Our research participants spoke of the laundry as a boring and repetitious process that never ends. Need to do laundry is ongoing. Nicole, mother of 3 school-age children, said, "There is always laundry there to be done. It's calling to me. It's like a constant pressure." Doing laundry is not an event with a special day devoted to its completion, such as Monday as laundry day, but rather a series of steps that carry overnight and often in continuous time. For example, women may wash and dry a tub of clothes one day and then fold and put them away the next day, but usually mothers are always in the midst of doing a laundry step and feeling intense pressure to pursue the next steps. This pressure to do the same thing over and over again leads to boredom. Constant pressure to accomplish a repetitive household chore makes the task a boring one.

Doing the laundry seems to fit into women's busy lives because mothers can complete steps in between their other activities. Yet, laundry always hovers in the background waiting to be done. Managing the laundry swings between chaos and organization. Chaos occurs when hampers overflow and there aren't enough clean clothes from which to choose. For instance, children may claim they have nothing to wear or as Jenny, mother of two teens said, "My son can come home from school asking, 'Mom, did you do the laundry today? I want to wear my new jeans tonight.'" On the other hand, the laundry process feels organized and under control when there are drawers full of clean clothes and the dirty 
clothes pile remains low. As a result of this constant movement between chaos and organization, managing the laundry elicits a flow of emotions, feeling in and out of control. Staying caught up with the laundry brings comfort while getting behind feels overwhelming.

Because laundry is done in steps, mothers can 'forget' about the laundry while engaged in their busy lives working in paid jobs, doing volunteer work, and being involved in their children's activities and other household tasks. For instance, Barbara, mother of 4 school-age children, commented that sometimes she forgets that she washed clothes, so forgets to put them in the dryer and then they become smelly and she has to wash them over again. Such forgetting increases the pressure and anxiety of keeping up with the laundry.

\section{Laundry steps and embodied experience}

The laundry process is parsed into steps, each with its own meaning and sense of completion, and overall sense of moving the process along. Steps are collecting, sorting, pre-treating, washing, drying, folding and putting away. There was variability among research participants in carrying out the steps, and mothers had personalized systems ranging from simple to complex, but the emotions in laundry practices were similar across the participant sample. Key embodied emotions were competence, caring, nurturance and love for family.

Collecting dirty clothes from everyone in the household starts a process of neatness. Lisa, mother of 3 school-age children, said that collecting dirty clothes is "similar to garbage day when you're getting dirt out of the house. This is dirt out of clothes." The act of collecting elicits feelings of caring about the family. Sorting clothes into different piles for washing emphasizes feelings of competence because mothers feel their knowledge of fabrics, textures and colors influences the outcome of making dirty clothes clean. Figure 1 shows how Lisa sorted her family's dirty clothes into three piles: whites, darks and reds. She thought that reds do not belong in the same pile as darks because red colored fabrics tend to bleed onto other clothes in the same washing load. 


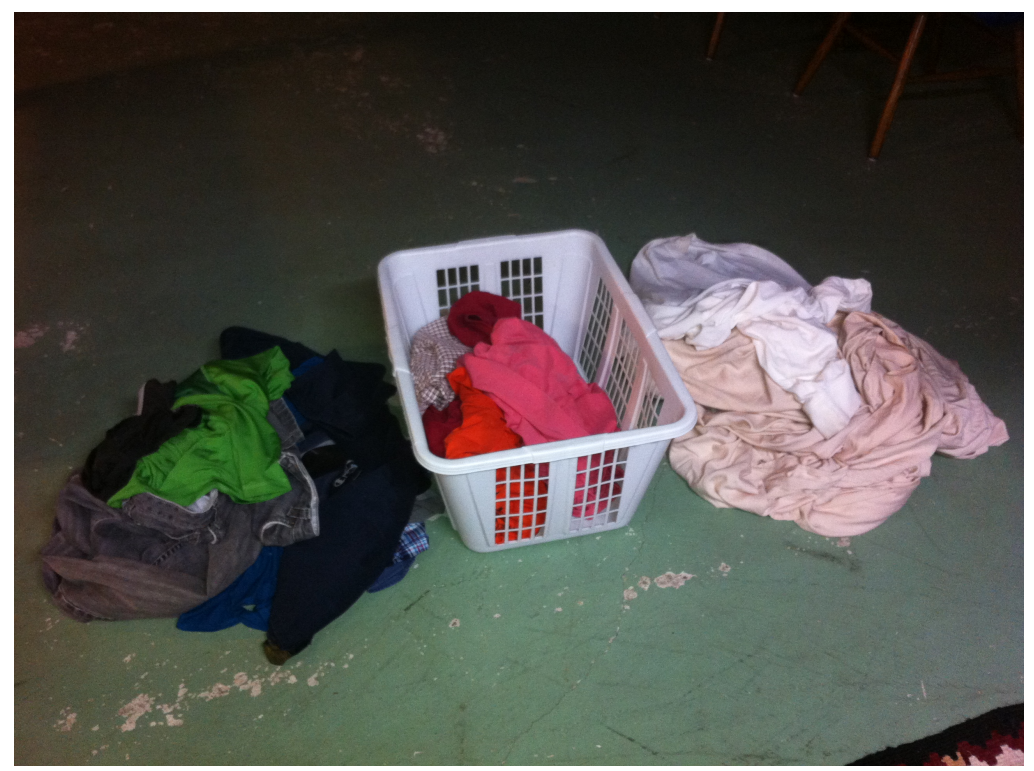

Figure 1. Sorting dirty clothes into three piles with red fabrics separate from darks and whites.

Touching clothes during the sorting and pre-treating steps often triggers mnemonics and remembrances of how the clothes got dirty. Memories of family moments re-create feelings of joy and love in lived experience. For example, Amy, mother of 3 pre-school children talked about dirty baby bibs and remembering her 6 month old baby spitting out the green vegetable puree that she tried feeding her and of dirt-stained clothes her other two children wore when they were making mud pies in the backyard. Pre-treating also brings up feelings of competence because of knowledge about commercial products and home remedies needed to remove stains from clothing. Similarly, use of washers and dryers involve the sensuous experience of touching clothes as well as competent feelings in making machine adjustments and adding products such as detergent, bleach, fabric softeners and dryer sheets. We learned from the tape diaries of participants that shopping in the laundry aisle of a supermarket is itself a sensual experience. A multitude of bright colors on commercial product labels attracts the eye and the fragrance in the whole aisle delights the sense of smell. However, decisions on purchase of specific brands are usually made prior to shopping, and brand loyalty often crosses generations. As a participant commented, "Tide worked well for my mother and it works well for me." Thus, mnemonics also plays a part in choice of laundry product brands.

Folding clean clothes is a potent sensual step in the laundry process, especially when clothing still feels warm from the dryer. As Nicole said, "It's warm and smells so nice." Folding also references laundry aesthetics. "Seeing the clothes come out clean, no stains, it looks so nice," said Kate, mother of two school-age children. Figure 2 shows a 
participant folding whites in her bedroom. The final step of doing the laundry, putting clean clothes away, involves touch, sense of accomplishment, and anticipation of cultivating subjectivity by helping children pick out what to wear. Lisa expressed this achievement and anticipation when she said, "I cleaned up the mess. The drawers are now full. The kids can choose their outfits."

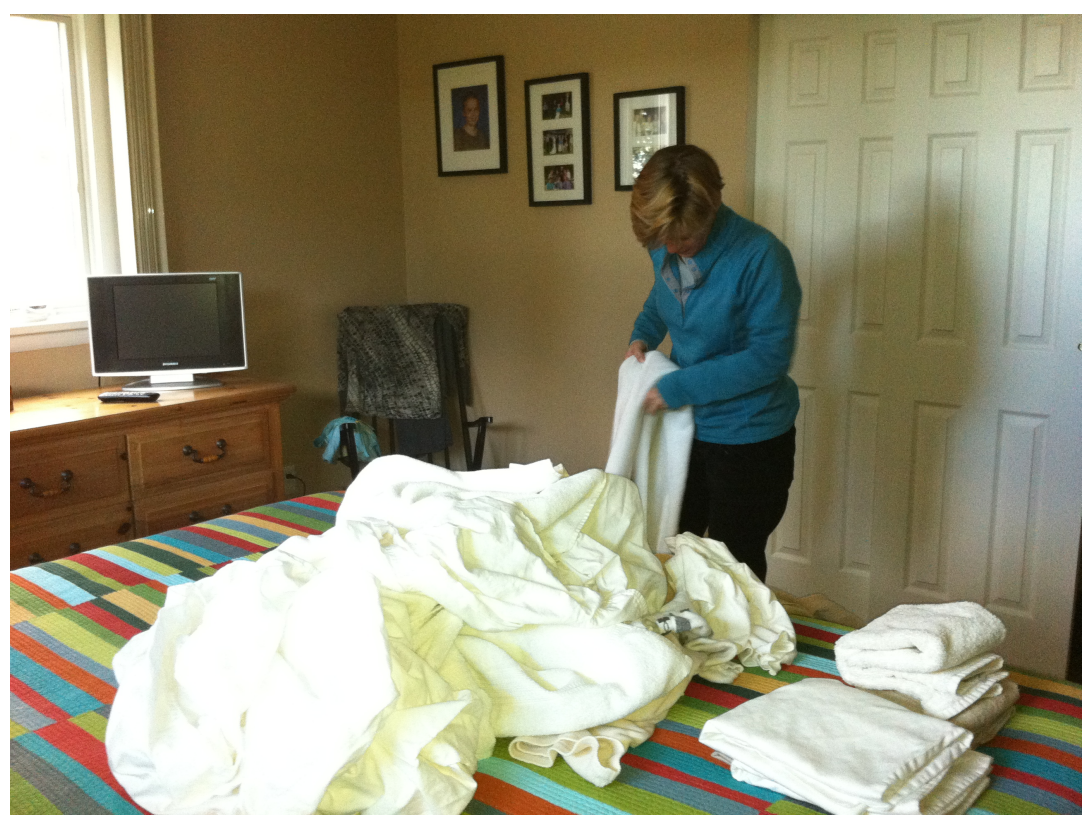

Figure 2. Folding a load of whites in the bedroom.

\section{Cultivating subjectivity}

Clean clothes provide a palette for constructing presentations of self, according to our participants. Mothers spoke of subjectivity as becoming aware of how you feel inside and projecting that on the outside when you get dressed in the morning. They wanted their children to learn how to select clothes with spontaneity, improvisation and creativity in expressing internal feelings and positioning to others. Learning how to do this, Barbara claimed, is "as important as breakfast". Participants said their morning conversations with children about choice of clothes involved talking about how children were feeling, what they were going to do and who they were going to spend time with that day.

The goal of the laundry ritual, then, is cultivating subjectivity in children. Enjoyment from doing the laundry comes ultimately from teaching this subjectivity and the effect of seeing one's children wearing the clean clothes they choose to wear in the world. As Kate said, "It's seeing the delight in your child's eyes, someone responding to him or her." The process of teaching children to develop self-awareness about clothes selection comprises an important part of the parenting role for mothers. Cultivating the subjectivity is "like tending a garden," added 
Kate. Mothers tend an emerging self-awareness in children about presenting the self as a clothed body.

\section{Standards of clean and owning the laundry}

The standard of clean used by participants was measured in an absolute way. Clothes should come out of the laundry looking "like when they were brand new," as Lisa described. In practical terms, clean meant not stained, not smelly, and not wrinkled. Laundry forms part of the conversation among female friends and family. Women tell laundry stories and ask each other about solving laundry problems such as how to remove specific kinds of stains and how to clean particular types of fabrics.

Participants complained about other family members not doing the laundry correctly, thereby jeopardizing the absolute standard of clean. For example, Amy said that her mother-in law doesn't pre-treat the dirty clothes so that stains remain; Jenny said that her adolescent daughter wants to do her own laundry but it "comes out a mess" because she sets the water level too low and leaves the clothes in the dryer too long so they become wrinkled; Kate said that her spouse doesn't sort the dirty clothes and "the whites turn gray"; and Barbara said that her husband doesn't use dryer sheets which leaves the clothes full of static. Improperly done laundry interferes with mothers' laundry goals to provide an array of clean clothes for presentation of self. As Nicole commented, "I have a say in how my family is presented to the world and that's more important than how my home looks. I'd let go of cleaning the house in order to take time to get out stains in the dirty clothes." The paradox of the laundry arises from the juxtaposition of a boring household chore against the failure of others to meet an aesthetic standard that is necessary for mothers to fulfill the goal of the laundry process.

As a result, women have a strong stake in retaining control over the laundry process. They prefer to do the laundry themselves or to limit participation by others. One way of limiting participation is letting others do a step not considered critical to the outcome such as throwing an already sorted load into the washer. Another means is letting others only do certain kinds of clothes such as spouse's work clothes or children's sports gear. Impetus for taking ownership of the laundry is caring about the family, how they look, and teaching the children to be aware of how they present themselves.

\section{Discourse of mothers and discourse of advertising}

Prior to conducting the ethnographic study of women's laundry practices, P\&G advertising discourse emphasized the agency of its product in cleaning dirty clothes. Tide was portrayed as the superior brand in the 
detergent category. In the discourse the effect of the product is tangible. However, while the agency of the product plays an important part in the discourse of mothers, the discourse also features the intangible goal of doing the laundry. The intangible goal of cultivating subjectivity in children calls for achieving the tangible goal of clothes cleaned according to an absolute standard of clean. For mothers, the intangible reward of seeing their children develop self-awareness about presentation of self ultimately provides the deeper meaning of the laundry process. The ethnographic research brought to light difference between the discourse of mothers and the discourse of advertising.

Upon the author's presentation of research results to the clients, discussion ensued with the $P \& G$ and Saatchi employees in attendance. The $P \& G$ personnel, who worked in the research, marketing and brand management departments of the company, talked about corporate investment in brand equity. They were initially intent on retaining focus on product superiority in communications with consumers and on safeguarding brand equity. In response, Saatchi representatives, who were account planners and members of the advertising agency's research division, spoke about creating breakthrough concepts for advertising based on thorough understanding of what motivates consumers. At this early stage of the discussion, the discourse of advertising and the discourse of mothers were cast as two competing discourses. For $P \& G$ personnel, the suggestion of shifting emphasis away from the product seemed to conflict with internal organizational belief in the product efficacy of its leading brand. Their pride in the brand rose to the surface in conversation.

As the discussion continued, the ethnographer pointed out the relationship between human agency and the agency of objects in the discourse of mothers. The research findings support the agency of laundry detergent as an object in women's discourse. We learned from observing laundry practices and listening to women's descriptions of shopping for laundry products in supermarkets that choosing detergent and other laundry products constitutes an important part of a mother's skill in getting dirty clothes clean. Emphasis on human agency and the goals of mothers do not necessarily exclude product agency. In fact, accomplishing the intangible goal depends on product efficacy. Cultivating subjectivity requires clothes returned to the absolute standard of clean to which mothers subscribe. Saatchi representatives stressed their aim of adding emotions from women's embodied experience to advertising communications in order to enhance the brand by stronger connection with the target audience. They argued that critical insights into laundry rituals would improve brand positioning and resonance with consumers. P\&G people, swayed by Saatchi arguments, began to entertain change in communications.

Figure 3 shows an advertising image that incorporates meaning 
from women's embodied experience at the same time as it celebrates legendary brand status and product power. The image acknowledges the importance to consumers of the clothed body looking good. As the text claims, "... Tide is always looking for innovative ways to get them [stains] out. From the powder of yesteryear to the Tide Pods of tomorrow, we're proud to keep you looking your best." In this communication, looking good is contingent on the power of detergent to remove stains from dirty clothes, and the message expands the expression of agency from singular point of reference (product) to a dual reference (product and human action in presentation of self). The advertising discourse adopts meaning constructed in the ritual performance of mothers doing the laundry.

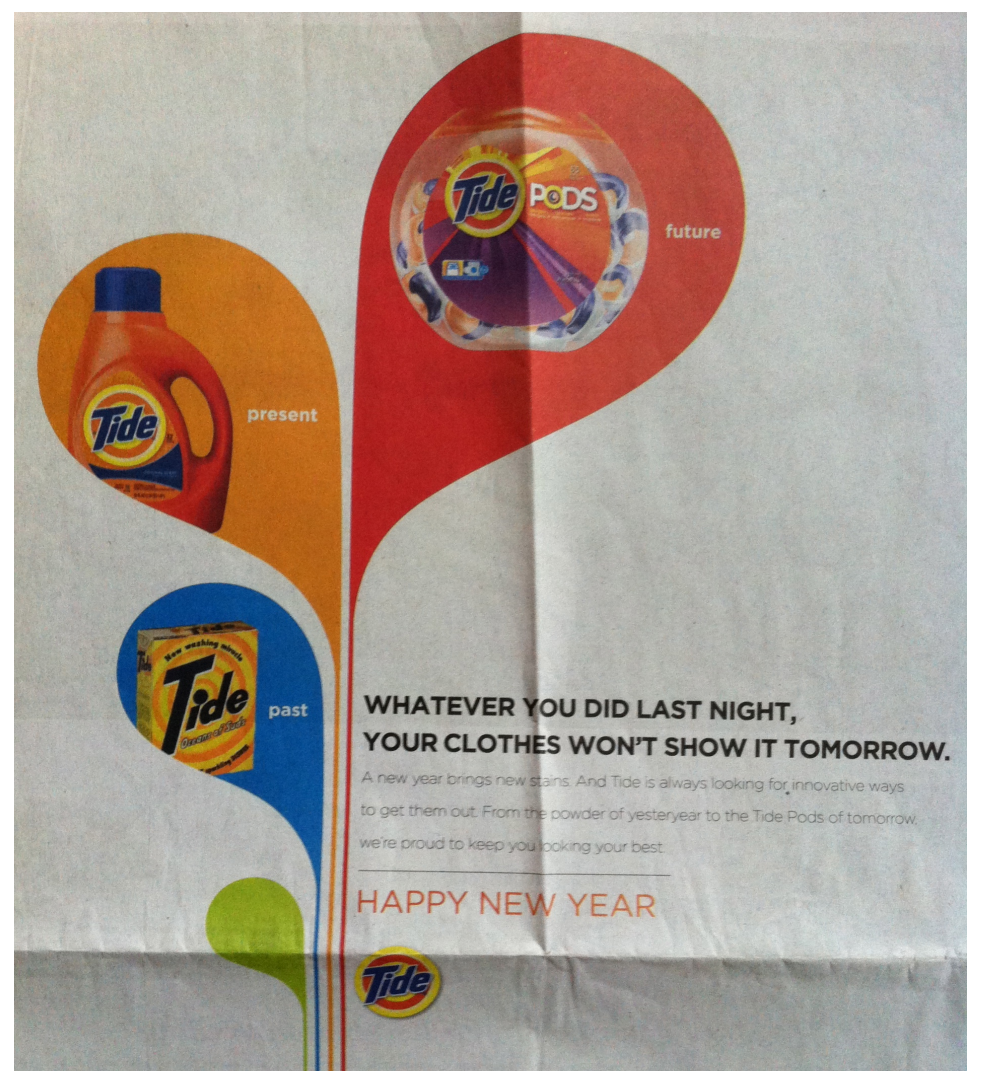

Figure 3. Meaning from women's laundry rituals seeps into advertising imagery.

\section{Discussion}

The laundry paradox and its contradictory feelings of hating to do laundry but not wanting others to do it are resolved through ethnographic understanding of laundry rituals. Mothers generate feelings of caring, nurturance and love of family during ritual acts that ignite and renew desire to cultivate subjectivity in their children about presentation of self to the world. To achieve this ritual goal of teaching self-awareness to children requires an array of clean clothes. Mothers find the laundry a boring task yet hesitate to relinquish the chore because the goal of 
cultivating subjectivity in children is stymied when others do the laundry incorrectly and dirty clothes do not come out clean to the absolute standard. As a result, women's laundry practices contain paradoxical elements that can prompt boredom, foster indignation and create sources of pleasure. Pleasure arises from the visual enjoyment of seeing clothes clean again, from the sensual aspects of doing the laundry such as smelling laundry product fragrances and touching clean and warm garments, and from achieving the ritual goal of guiding children in the process of getting dressing.

Explanation of the paradox relies on two analytic perspectives. One is a cognitive approach to understanding behavior through cultural systems of classification, which in this case identified the categories of action or steps in doing the laundry and the standard of clean followed in women's laundry practices. The other perspective is an embodied approach to interpreting practices through the interplay of the senses and emotions. The embodied experience of women's laundry rituals revealed feelings, meanings and values generated as mothers do the laundry. With a paradigm of embodiment the analysis shifts, as Csordas (1990) writes, "from perceptual categories and questions of classification and differentiation to perceptual process" (1990: 35). Emotions generated in laundry rituals explain why having the laundry done correctly matters to women. Clean clothes are key to developing awareness in children about getting dressed as a reflexive act expressing emotions and identity through clothing choices.

Embodied sensibility crosses perceptions of time. When mothers touch, smell, hear and see dirty clothes in the process of becoming clean, they connect past, present and future. Through mnemonics and remembering social occasions when dirty clothes were worn in the past and imagining drawers full of clean clothes to be used for cultivating subjectivity in the future, mothers place themselves in the ambit of passing time. In his analysis of family meals as acts of remembrance on the Greek island of Kakymnos, David Sutton (2001) notes that repetitive and transitory tasks become enduring acts of remembering and identity. In the case of the laundry, ritual time projects backwards to family memories and forwards to anticipations of clothed bodies performing identity. Daniel Miller (2009) points out that clothing can reframe our sense of time; for example, buying distressed jeans fends off linear time with the patina of a well-worn garment. The ritual of doing the laundry suppresses time with memories of when dirty clothes were worn and expands time by opening horizons to future occasions of getting dressed with clean clothes.

Use of branded products spans relationships across generations through the power of nostalgia (Olsen 1993, 1999). Brand loyalty toward Tide runs high in the laundry detergent category, and this study concurs with the importance of family influence on brand loyalty. Olsen (1993) 
finds that over time "a branded good becomes a 'bundle of satisfactions' including memories and meanings that get wrapped around its advertised use value to solve problems with various benefits. These memories and meanings include individuals and contexts associated with its use" (1993: 577). In the case of the laundry, memories involve smells of home such as laundry product fragrances and meanings associated with mother and her laundry practices. As Olsen (1999) states, nostalgic attachments to cleaning supplies "give superior authority to accomplish the task" (1999: 619). The role of mothers and their command of the laundry process often lead to transferring brand loyalty through subsequent generations.

Rituals mediate embodied practices, emotions and discourses. The ethnographic research of women's laundry rituals uncovered difference between the discourse of mothers and the discourse of advertising. P\&G communications emphasized the agency of objects while the discourse of mothers highlighted human agency as well as the agency of objects. Implementing ethnographic practice in advertising media involves the production of culture. P\&G incorporated meaning from women's laundry rituals in new messages to its target audience which created a bridge between embodied feelings generated in the ritual experience and cultural meanings circulating in advertising discourse. As Malefyt and Moeran (2003) state, advertising strategy "positions the product in relation to targeted consumers and emphasizes the attributes that will appeal to them" (2003: 5). The implementation of ethnographic practice in advertising makes manifest the role of mimesis in producing cultural realities. Laundry rituals are mimetic performances by the laundry detergent and by the mother. Working together they re-enact rituals of rebirth; the product regenerates clothes and the act of washing the clothes renews sensorial experiences and emotions.

Given the white middle-class demographic target of this ethnographic study, further research beyond white middle-class mothers is warranted. Since clothes carry class distinctions and hegemonic identities (Bourdieu 1984), additional study would reveal how women from other social classes and ethnic backgrounds relate to laundry. Such research would heed a call from third-wave feminism and its concern with intersectionality by exploring contingencies of identity categories such as gender, social class and ethnicity (Lewin and Silverstein 2016).

In addition, research among men would provide insight on how males perceive the laundry process, which is an important issue given changing gender roles as increasing numbers of women participate in the labor force and many men share more household responsibilities. In particular, it would be useful to learn the ritual goal of fathers in doing the laundry compared to the goal of mothers for whom the cultivation of subjectivity in children is paramount. Is there gendered difference in conceiving and pursuing interests in laundry practices? Joanne Entwistle (2015) argues that women are more closely identified with the body than 
men (2015: 22) and that consciousness of bodily appearance is gendered because women more than men view their bodies as objects for the gaze of others which informs choices women make when getting dressed for some situations (2015: 31). Are fathers like mothers in privileging clean clothes for the purpose of teaching children about dress, internal feelings and identity, and external appearance and the gaze of others?

Annette Weiner (1992) observes that power is intimately involved in cultural production of cloth and clothing. The degree of control over cloth coincides with rank and the development of hierarchy in the Polynesian community where she conducted ethnographic research. Weiner claims that a woman wearing certain clothing, such as the Maori ceremonial cloak, not only wears herself but also her ancestors. Following a similar cultural logic, children wearing clothes sorted and cleaned by the mother represent the family clan. This study suggests that there is a dual sense of wearing clothes prepared by the mother. Clothing is layered on the surface of the body in a process where family members assemble themselves in layers and sequences, and the mother is guide and agent for the process. In this sense, the mother remains connected and present with the body, close to the family member, yet also exposed to public approval. By teaching their children how to dress in relation to social expectations determined by frames that constitute the context of action (Goffman 1974), mothers expose themselves to the critical gaze of others. Management of self in front of others places mothers in a position to be judged by other mothers according to social standards defining laundry outcomes. These social standards are influenced by widespread advertising discourse that emphasizes the agency of laundry products in attaining an absolute standard of cleanliness. Women's laundry practices manifest power insofar as children attired in clothes cleaned at home represent the family and display in public a mother's competence or lack of competence in getting clothes clean. Other mothers assume the power to judge and criticize her laundry practices.

\section{Conclusion}

Consumption draws attention to materiality and the relationship between people and things. Laundry practices, in particular, shed light on the role of materiality in clothing the body (Entwistle 2015) and the creation of subjectivity (Mascia-Lees 2016). The laundry paradox reveals engagement between the material and the social because of the importance that mothers give to doing the laundry correctly and teaching children about getting dressed.

In anthropology there is renewed interest in materiality and material culture with effort to overcome the subject-object binary. This interest is called the material culture turn (Hicks 2010) and the rise of the thing (Holbraad 2011). Concern with materiality and material culture 
refers, as Geismar (2011) states, "to a vision of human experience in which subjectivity is profoundly material” (2011: 212). Recent anthropological discussion articulates three perspectives on the relationship between humans and things: (1) materiality as representation, which is reflected in classic ethnographies such as Turner's (1967) study of Ndembu people in Zambia and Weiner's study of Trobriand Islanders who live off the coast of Papua New Guinea; (2) materiality as agent entangled in a network, assemblage or social field of actors, an approach theorized by Latour (1993), Gell (1998) and Miller (2005); and (3) materiality as agent whose physical properties and qualities give things agency commensurate with humans, which is argued by Holbraad (2011), Hodder (2012) and Ingold (2013) and influenced by Viveiros de Castro (2009) and the position based on his research among people in the Andean highlands that things are not representations but ontological alternatives for defining reality. My intention here is to indicate relevance of the perspectives to understanding women's laundry practices and insight into materiality of the clothed body.

Women's laundry practices express materiality in terms of representation and agency in assemblages, the first and second perspectives above. Garments are symbols as dirty and clean clothes in the cultural system of classification for steps in doing laundry. Garments are also symbols of identity chosen to represent the self when getting dressed. The laundry assemblage involves many actors including those described in this essay such as items of clothing, commercial laundry products, washing and drying machines, mothers, children and other family members, laundry rituals, mother's knowledge and skill in getting clothes clean, and discourse on advertising touting the power of branded products in the cleaning process; another agent in the assemblage not mentioned here is water, the ultimate ritual purifier and sacred symbol of change in many cultures. Laundry practices bring together all these elements, sacred and profane, commingling commercial brands, human agency, machines and nature. Interaction occurs among actors in the assemblage. For example, laundry machines have changed over the years. They are no longer cold and distant but warm and aesthetically friendly (Postrel 2003). They cooperate with us and aid us with sensors that adapt water levels, temperatures, length of wash time and informative signals (beeps and buzzes) that talk back to us. Understanding the agency of things in assemblages depends on context. As Geismar (2011) writes, “ Time, place, history, and space are all shown to matter in the ways in which artifacts are given meaning and how they then, imbued with meaning, become social actors" (2011: 216). In this sense, items of clothing become agents because they reflect the human intentions of designers, manufactures and consumers. At the same time, material characteristics of garments afford and constrain movement in the laundry assemblage according to the third perspective above. Such material characteristics include fabric properties, color, and shape affecting 
laundry practices as well as dressing practices. For example, silk and cotton drape differently on the body and call for different cleaning methods. As a result, through laundry practices, mothers accomplish ritual goals in concert with other agents in the laundry assemblage. All three perspectives on materiality above add explanatory power to the paradox of the laundry.

Tim Ingold (2012) talks about physicality and meaning in terms of movement, which applies to the laundry process. He writes, “...neither thoughts, nor gestures, nor spoken words, not even things are discrete objects strung in time like a string of beads. Rather, thinking is a process that carries on, as do movement, speech and the materials of which things are made" (2012: 439). Humans and things exist in a state of becoming, and persons correspond with things around them in various contexts. In the laundry process, clothes are in continuous movement (e.g., from dirty to washed, dried, restored to original or washed but still stained, folded, donned again). Likewise, for people, getting dressed everyday is a process of becoming as clothes are chosen to reflect inner feelings and outward presentation of self. We know ourselves through movement. Getting dressed is precisely what mothers intend to teach their children-getting dressed everyday as a daily "situated bodily practice" (Entwistle 2015: 5). Consumer culture recognizes the body as an unfinished entity open to change (Featherstone 1991); providing clean clothes and getting dressed complete the body everyday.

Daniel Miller, whose Material Culture and Mass Consumption (1987) led the anthropological endeavor to establish material culture studies as a discursive field, refers to the "tyranny of the subject" and emancipating things by association with humans and integrating materiality with sociality (2005: 3). His work on the social life of clothing (Miller and Woodward 2012, Kuchler and Miller 2005) shows how social relations are created through consumption activities. He claims that the clothed body "forces us to acknowledge the centrality of materiality itself to the constitution of humanity" (Miller 2005: 34). Women's laundry practices indicate that children learn from their mothers the meanings of things when getting dressed. In his essay on body techniques, Mauss (1979) recognizes that children imitate and learn bodily actions from adults in whom they have confidence and who have authority over them (1979: 101-102). Further, Urban's (2010) notion of 'culture in motion', referring to the transmission of practices to other people through processes of social learning, assumes that acquisition of cultural elements occurs through the power of authority and obeying commands (2017:

13). He writes, the motion of cultural elements may happen through force as self-regulation, "a pre-programming of individuals or the prior inculcation in them of a disposition to conduct themselves in a certain way" (2017: 14). Learning to get dressed is a complex behavior that brings together clothing, the body and performance as embodied practice 
(Hansen 2004). When mothers cultivate subjectivity in children, they emphasize getting dressed as a reflexive practice that pays attention to emotions, identity and presentation of self to the world. Women's laundry practices affirm the clothed body as a unitary phenomenon, a way of communicating through materiality; doing the laundry and teaching children to construct themselves when getting dressed attests to the relationship between subjectivity and materiality.

\section{References}

Ahearn, L. M. 2001 'Language and agency.' Annual Review of Anthropology 30: 109-37. https://doi.org/10.1146/annurev.anthro.30.1.109

Bourdieu, P. 1984 Distinction: a social critique of the judgement of taste. Cambridge: Harvard University Press.

Csordas, T. J. 1990 'Embodiment as a paradigm for anthropology.' Ethos 18 (1): 5-47. https://doi.org/10.1525/eth.1990.18.1.02a00010

Csordas, T. J. 2012 'Psychoanalysis and phenomenology.' Ethos 40 (1): 5474. https://doi.org/10.1111/j.1548-1352.2011.01231.x

DeVault, M. L. 1991 Feeding the family: the social organization of caring as gendered work. Chicago: University of Chicago Press.

De Witte, M. 2011 'Touched by the spirit: converting the senses in a Ghanaian Charismatic Church.' Ethnos 76 (4): 489-509. https://doi.org/10.1080/00141844.2011.620711

Desjarlais, R. and C. J. Throop. 2011 'Phenomenological approaches in anthropology.' Annual Review of Anthropology 40: 87-102. https://doi.org/10.1146/annurev-anthro-092010-153345

Douglas, M. 1966 Purity and danger: an analysis of concepts of pollution and taboo. London: Routledge. https://doi.org/10.4324/9780203361832

Entwistle, J. 2015 The fashioned body: Fashion, dress \& modern social theory, 2nd ed. Cambridge: Polity.

Featherstone, M. 1991 'The body in consumer culture.' In M.

Featherstone, M. Hepworth and B.S. Turner (eds.) The body: social process and cultural theory, pp. 170-196. London: Sage.

https://doi.org/10.4135/9781446280546

Geismar, H. 2011 "'Material culture studies'; and other ways to theorize objects: a primer to a regional debate." Comparative Studies in Society and History 53(1): 210-218. https://doi.org/10.1017/S001041751000068X

Gell, A. 1998 Art and agency: an anthropological theory. Oxford: 
Clarendon Press.

Goffman, E. 1956 The presentation of self in everyday life. New York: Doubleday.

Goffman, E. 1974 Frame analysis: an essay on the organization of experience. Cambridge: Harvard University Press.

Handelman, D. and G. Lindquist (eds.) 2005 Ritual in its own right: Exploring the dynamics of transformation. New York: Berghahn.

Hansen, K.T. 2004 'The world in dress: anthropological perspectives on clothing, fashion, and culture.' Annual Review of Anthropology 33: 369-92 https://doi.org/10.1146/annurev.anthro.33.070203.143805

Hicks, D. 2010 'The material-cultural turn: Event and effect.' In D. Hicks and M.C. Beaudry (eds.) The Oxford handbook of material culture studies, pp. 25-98. Oxford: Oxford University Press.

Hochschild, A. R. 1989 The second shift: working families and the revolution at home. New York: Viking.

Hodder, I. 2012 Entangled: an archeology of the relationships between humans and things. Malden: Wiley-Blackwell. https://doi.org/10.1002/9781118241912

Holbraad, M. 2011 Can the thing speak? Open Anthropology Cooperative Press. openanthcoop.net/press/2011/01/12/can-the-thing-speak/ accessed March 12, 2017.

Holland, D. and K. Leander. 2004 'Ethnographic studies of positioning and subjectivity: an introduction.' Ethos 32 (2): 127-139.

https://doi.org/10.1525/eth.2004.32.2.127

Ingold, T. 2012 'Toward an ecology of materials.' Annual Review of Anthropology 41: 427-442. https://doi.org/10.1146/annurev-anthro$\underline{081309-145920}$

Ingold, T. 2013 Making: anthropology, archeology, art and architecture. London: Routledge.

Kuchler, S. and D. Miller. 2005. Clothing as material culture. Oxford Berg. https://doi.org/10.2752/9780857854056

Latour, B. 1993 We have never been modern. Cambridge: Harvard University Press.

Lewin, E. and L. M. Silverstein. 2016 Mapping feminist anthropology in the twenty-first century. New Brunswick: Rutgers University Press.

Luhrmann, T. M. 2006 'Subjectivity.' Anthropological Theory 6 (3): 345361. https://doi.org/10.1177/1463499606066892

Malefyt, T. and M. McCabe. 2016 'Women's bodies, menstruation and marketing "protection:" interpreting a paradox of gendered discourses in consumer practices and advertising campaigns.' Consumption Markets \& 
Culture 19 (6): 555-575.

https://doi.org/10.1080/10253866.2015.1095741

Malefyt, T. and B. Moeran. 2003 'Introduction: Advertising culturesadvertising, ethnography and anthropology.' In T. Malefyt and B. Moeran (eds.) Advertising cultures, pp. 1-33. Oxford: Berg.

Maschio, T. 2015 'Everyday things: an anthropologist's take on emotion and the sense of the sacred in consumer rituals.' Journal of Business Anthropology 4 (2): 342-351. https://doi.org/10.22439/jba.v4i2.4896

Mascia-Lees, F. E. 2016 'The body and embodiment in the history of feminist anthropology.' In E. Lewin and L. M. Silverstein (eds.) Mapping feminist anthropology in the twenty-first century, pp. 146-167. New Brunswick: Rutgers University Press.

Mauss, M. 1979 'Body techniques.' In Sociology and psychology, essays by Marcel Mauss (trans. B. Brewster) pp. 95-123. London: Routledge

Miller, D. 1987 Material culture and mass consumption. Oxford: Basil Blackwell.

Miller, D. 2005 'Introduction.' In D. Miller (ed.) Materiality, pp.1-50. Durham: Duke University Press. https://doi.org/10.1215/9780822386711-001

Miller, D. 2009 'Buying time.' In E. Shove, F. Trentmann and R. Wilk (eds.) Time, consumption and everyday life: practice, materiality and culture, pp.157-169. Oxford: Berg.

Miller D. and J. Woodward. 2012 Blue jeans: the art of the ordinary. Berkeley: University of California Press. https://doi.org/10.1525/california/9780520272187.001.0001

Miyazaki, H. 2004 The method of hope: anthropology, philosophy and Fijian knowledge. Stanford: Stanford University Press.

Moeran, B. 1997 Folk art potters of Japan: beyond an anthropology of aesthetics. Honolulu: University of Hawaii Press.

Olsen, B. 1993 'Brand loyalty and lineage: exploring new dimensions for research.' In L. McAlister and M.L. Rothschild (eds.) Advances in Consumer Research Volume 20, pp. 575-579. Provo UT: Association for Consumer Research.

Olsen, B. 1999 'Exploring women's brand relationships and enduring themes at mid-life.' In E.J. Arnould and L.M. Scott (eds.) Advances in Consumer Research Volume 26, pp. 615-620. Provo UT: Association for Consumer Research.

Postrel, V. 2003 The substance of style: how the rise of aesthetic value is remaking commerce, culture and consciousness. New York: HarperCollins. 
Potter, J. 2004 'Discourse analysis as a way of analyzing naturally occurring talk.' In D. Silverman (ed.) Qualitative research: theory, method and practice, 2nd ed., pp. 200-221. London: Sage.

Quine, W. V. 1966 The ways of paradox and other essays. Cambridge: Harvard University Press.

Skoggard, I. and A. Waterston. 2015 'Introduction: toward an anthropology of affect and evocative ethnography.' Anthropology of Consciousness 26 (2): 109-120. https://doi.org/10.1111/anoc.12041

Stewart, P. J. and A. Strathern. 2014 Ritual: key concepts in religion. London: Bloomsbury.

Sutton, D. E. 2001 Remembrance of pasts: an anthropology of food and memory. Oxford: Berg. https://doi.org/10.5040/9781350044883

Svasek, M. 2005 'Introduction: emotions in anthropology.' In K. Milton and M. Svasek (eds.) Mixed emotions: anthropological studies of feelings, pp. 1-23. Oxford: Berg.

Thompson, C. J. and D. L. Haytko. 1997 'Speaking of fashion: consumers' uses of fashion discourses and the appropriation of countervailing cultural meanings.' Journal of Consumer Research 24 (1): 15-42. https://doi.org/10.1086/209491

Turner, V. 1967 The forest of symbols: aspects of Ndembu ritual. Ithaca: Cornell University Press.

Urban, Greg. 2010 A method for measuring the motion of culture. American Anthropologist 112(1): 122-139. https://doi.org/10.1111/j.1548-1433.2009.01201.x

Urban, Greg. 2017 Corporate compliance as a problem of cultural motion. Rutgers University Law Review 69(2): 1-37.

Van Maanen, J. 2011 Tales of the field: on writing ethnography, 2nd ed. Chicago: University of Chicago Press. https://doi.org/10.7208/chicago/9780226849638.001.0001

Viveiros de Castro, E. 2009 'The gift and the given: three nano-essays on kinship and magic. In S. Bamford and J. Leach (eds.) Kinship and beyond: the genealogical model reconsidered, pp. 237-268. New York: Berghahn.

Weiner, A B. 1992 Inalienable possessions: the paradox of keeping-whilegiving. Berkeley: University of California Press. https://doi.org/10.1525/california/9780520076037.001.0001 


\section{Acknowledgements}

The author thanks the anonymous reviewers for their insightful comments on a previous draft of this essay. The author also gives thanks to Penelope Queen and Myra Stark of Saatchi \& Saatchi Advertising for initiating a long-term collaboration on ethnographic projects for the agency's clients.

Maryann McCabe, Ph.D., is founder and principal of Cultural Connections LLC, a consumer research consultancy, and also Research Associate, Department of Anthropology, University of Rochester. She is co-editor of Cultural Change from A Business Anthropology Perspective (2018) and editor of Collaborative Ethnography in Business Environments (2017). She may be reached at $\underline{\text { mm@cultureconnex.com. }}$ 